\title{
Possibilidades de Contribuição do Design em Arranjos Produtivos Locais: um estudo de caso no setor de gemas e joias.
}

\author{
Raquel Pereira Canaan \\ Universidade do Estado de Minas Gerais \\ raquel.pcanaan@gmail.com \\ Maria Bernadete Teixeira \\ Universidade do Estado de Minas Gerais \\ teixeira.berna@gmail.com
}

Resumo: Este artigo é a síntese de estudos e pesquisas desenvolvidos no âmbito de um projeto de Mestrado em Design e do Centro de Estudos em Design de Gemas e Joias relacionados à inserção do design em Arranjos Produtivos Locais. Os projetos integram ações de pesquisa e extensão em arranjos produtivos de base mineral, especificamente gemas e joias, com o objetivo de identificar possibilidades de inovação social e produtiva a partir da ativação de aspectos e valores particulares ao território do arranjo. As possibilidades apontadas apoiam-se em dois estudos de caso realizados em APLs de Gemas e Joias de regiões mineradoras.

Palavras-chave: Arranjos Produtivos Locais, Inserção do Design, Inovação Social e Produtiva.

\begin{abstract}
This article is a synthesis of studies and researches developed within a project of Masters in Design and in the Study Center of Design Gems and Jewelry related to integration of design in Local Productive Arrangements. The projects are part of research and extension actions in productive arrangements mineral based, specifically gems and jewelry, with the objective of identifying opportunities for social and productive innovation from the activation of the particular aspects and values of the arrangement's territory. Chances pointed rely on two case studies in clusters of Gems and Jewels of mining regions.
\end{abstract}

Keywords: Local Production, Insertion of Design, Social and productive Innovation.

\section{INTRODUÇÃO}

Por se tratar de uma atividade projetual que lida com as interações e inovações sociais, o design tem como principal objeto a sociedade como um todo, considerando 
as expectativas e limitações particulares de cada grupo que a conforma. Segundo Laundry e Emude (2006) apud Krucken (2009), a inovação social consiste em mudanças no modo como os indivíduos ou comunidades agem para resolver seus problemas ou criar novas oportunidades. Exemplo disso são os movimentos slow (slow food, slow tourism, cittá slow), comunidades e economia criativas, comércio justo e arranjos produtivos locais.

Os Arranjos Produtivos Locais $(\mathrm{APL})^{1}$ consistem no conjunto de um número significativo de empreendimentos e indivíduos que atuam em torno de uma mesma atividade produtiva (Termo de Referência para Política Nacional de Apoio ao Desenvolvimento de Arranjos Produtivos Locais - APL) ${ }^{2}$. Segundo este documento, uma das vertentes da estratégia de atuação do Governo Federal para o desenvolvimento do país consiste na realização de ações integradas de políticas públicas para Arranjos Produtivos Locais. A atuação em APLs, nesse sentido, valoriza a cooperação, o aprendizado coletivo, o conhecimento tácito e a capacidade inovativa das empresas e instituições locais como questões centrais para o aumento da competitividade sustentável, fortalecendo os mecanismos de governança. Arranjos produtivos consolidados localmente indicam desenvolvimento e geração de vantagens, emprego e renda. Brito (2002) apud Dalla Vecchia (2008) aponta que a estruturação dos arranjos estimula processos de aprendizado coletivo em nível local, que viabilizam o aumento da eficiência produtiva. $\mathrm{O}$ autor justifica a necessidade de intensificar as articulações e interações nessas aglomerações por propiciar geração e qualidade de empregos em nível local, contribuindo para a dinamização de espaços econômicos.Os APLs englobam diversas parcerias possíveis/estabelecidas, as quais formam a base que sustenta e contribui para o seu desenvolvimento e de suas regiões. Hoje, identifica-se uma grande variedade de aglomerações produtivas em todo o país, porém estas atuam de forma isolada. Para que se torne possível seu desenvolvimento de forma sustentável (ambiental e economicamente), é necessária a sua associação de forma mais organizada.

Os principais resultados das pesquisas realizadas pela RedeSist ${ }^{3}$ em diferentes regiões do país, segundo Lastres e Cassiolato (2005) confirmam que essa articulação e o aproveitamento das sinergias geradas por suas interações fortalecem as chances de sobrevivência e crescimento do APL, tornando-se importantes e duradouras vantagens competitivas. Estas pesquisas, no entanto, não se referem às potenciais contribuições do design ao desenvolvimento dos APLs. Durante os estudos e projetos referidos neste trabalho verificou-se também a escassa literatura sobre o assunto e poucos registros sobre as potenciais contribuições do design ao desenvolvimento econômico e social de unidades produtivas do setor, estas em sua maioria de pequeno porte e em regiões mineradoras de baixo Índice de Desenvolvimento Humano (IDH).

\footnotetext{
${ }^{1}$ Este termo representa a consolidação das discussões de um Grupo de Trabalho sobre a proposta de atuação integrada de políticas públicas em arranjos produtivos locais

${ }^{2}$ Este termo representa a consolidação das discussões de um Grupo de Trabalho sobre a proposta de atuação integrada de políticas públicas em arranjos produtivos locais

${ }^{3}$ Rede de pesquisa interdisciplinar sediada no Instituto de Economia da Universidade Federal do Rio de Janeiro e que conta com a participação de várias universidades e institutos de pesquisa no Brasil, alem de manter parcerias com outras organizações internacionais.
}

Fonte: http://www.redesist.ie.ufri.br/ Data de acesso: 21/04/2012 


\section{DESENVOLVIMENTO}

Considerando as condições atuais do planeta, Thackara (2008) já questionava o papel dos designers, defendendo serem estes os atores sociais que lidam com as interações cotidianas dos seres humanos com seus artefatos. Na projetação do futuro, o designer deve considerar o indivíduo entre o artefato e a natureza, desenvolvendo possibilidades alternativas na construção de uma relação diferenciada entre patrimônio biológico, cultura material e simbólica. Assim, a inovação em design deve garantir uma resposta às diferentes necessidades das pessoas e, como consequência, melhorar não só as experiências individuais como também a qualidade de vida da sociedade em geral.

Desde os anos 1970, a sustentabilidade vem sendo discutida no âmbito da atividade projetual do design. Porém, nos últimos tempos, ganhou maior abrangência, juntamente com os novos valores e movimentos que entraram em questão na sociedade atual, como a regeneração da qualidade do ecossistema global e dos contextos locais em que estamos inseridos MANZINI (2008,p.27).

Nesse sentido, as questões de sustentabilidade têm sido discutidas nos diversos ambientes produtivos, na esfera governamental e pela sociedade em geral, em busca de soluções que tragam benefícios econômicos, sociais, políticos e ambientais.

$\mathrm{O}$ aumento crescente da demanda por produtos diferenciados, acelerado pela competitividade que advém do processo contínuo de globalização, despertou a atenção para a preservação da tradição e das culturas e produtos locais, fortalecendo os movimentos de identificação cultural. Alcoforado (2010) afirma que dessa situação surgem novas formas de organização social, comunidades conectadas a uma realidade global, mas, que conservam características peculiares, redefinindo o termo local (p. 01)

Fleury e Fleury (2004) trazem o tema pensar globalmente, agir localmente, utilizado por muitas literaturas, que se traduz na busca por competitividade global, aprendizagem, inovação e retorno local. O design contribui para converter traços culturais em modos de agregar valor aos produtos, atuando como uma ferramenta de promoção do território, vertente que originou o conceito de design aplicado ao território.

Considerando que a capacidade inovativa está diretamente relacionada à ação do design, esta pode se constituir em importante estratégia de diferenciação e agregação de valor a aspectos significativos do APL, atribuindo-lhes sentido e ativando significados.

No âmbito complexo de um $A P L$, com diversas necessidades, atividades e recursos materiais e humanos, o design pode atuar em diferentes níveis, por meio de uma gestão coordenada e integradora.

Este artigo busca apontar possibilidades de inserção do design identificadas nesse tipo de organização,que podem contribuir tanto para seu desenvolvimento econômico e social, como para a valorização de seu potencial cultural, humano e material.

\subsection{Arranjos Produtivos Locais}

Dentre as formas utilizadas para designar as aglomerações e concentrações produtivas, encontram-se distritos industriais (MARSHALL, 1996), clusters (PORTER, 1998), arranjo produtivo e inovativo local (LASTRES, 2004), sistema local de produção (SUZIGAN et al, 2004), dentre outros. O conceito de Arranjo Produtivo Local é 
abordado por outros autores, apresentando divergências entre si. Um ponto em comum entre a maioria dos conceitos é a ideia de estruturas produtivas, onde se estabelece um relacionamento cooperativo entre empresas, universidades e centros de pesquisa em que treinamento, financiamento e gestão são usados como fator indutor de processos de produção e/de conhecimento em um ambiente inovador.

Segundo Lastres e Cassiolato (2005), Sistemas Produtivos e Inovativos Locais são conjuntos de agentes econômicos, políticos e sociais, localizados em um mesmo território e que desenvolvem atividades econômicas correlatas apresentando vínculos expressivos de produção, interação, cooperação e aprendizagem, evidenciando a visão sistêmica do processo, destacada por Tatsch (2010). É importante acrescentar a definição de Eurada (1999) apud Vahl (2009) que destaca, além da especialização em torno de um produto base, a interação entre atores, ambiente social e cultural local em função da qualidade de vida na região, não se restringindo apenas a negócios. Suzigan (2004) ressalta a interação, cooperação e aprendizagem no interior do aglomerado como forma de gerar a capacidade inovativa.

A Redesist é uma das pioneiras no estudo sistemático de APLs no Brasil e, neste estudo, adota-se sua definição para Arranjos Produtivos Locais como aglomerações territoriais de agentes econômicos, políticos e sociais com foco em um conjunto específico de atividades econômicas que apresentam vínculos, mesmo que incipientes. Geralmente, envolvem participação e interação de empresas produtoras de bens e serviços, fornecedoras de insumos e equipamentos e prestadoras de consultoria e serviços, dentre outras. Estão incluídas também instituições públicas e privadas voltadas à formação e capacitação de recursos humanos, tais como escolas técnicas e universidades, institutos de pesquisa, de desenvolvimento e engenharia, de política, promoção e financiamento.

O GASPIL (Glossário de Arranjos e Sistemas Produtivos e Inovativos Locais) indica as principais peculiaridades que devem ser observadas no estudo dessas aglomerações, apresentados no quadro da figura 1.

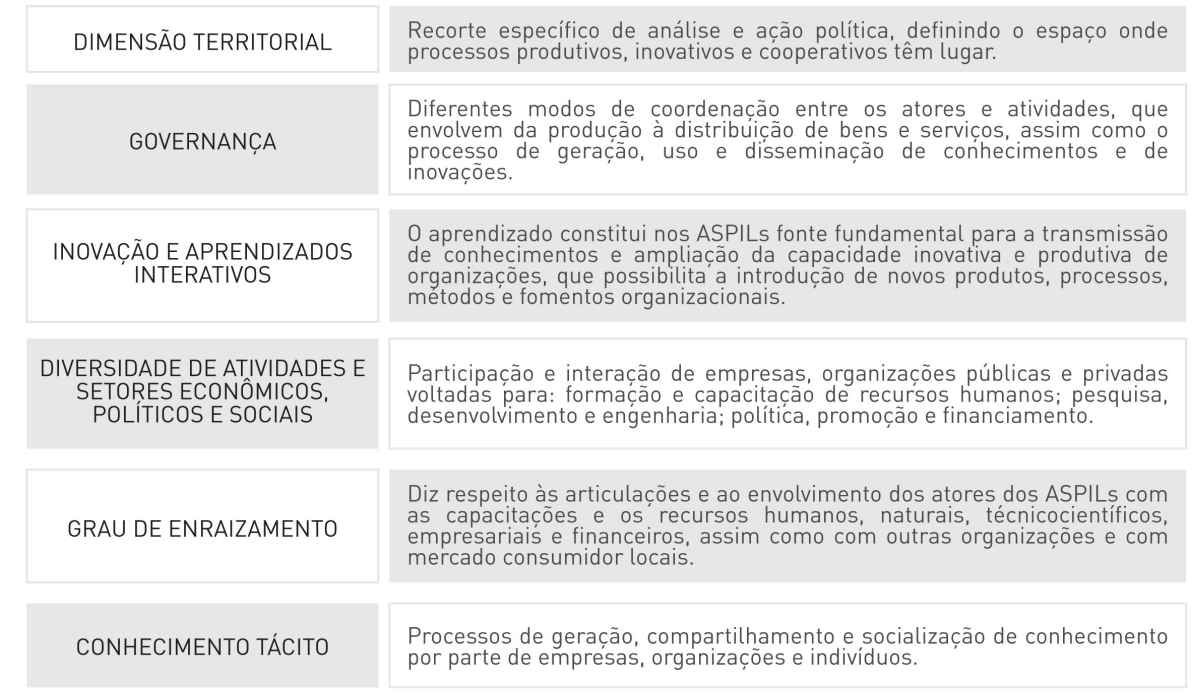

Figura 1 - Caracterização de ASPILs de acordo com o GASPIL. Elaborado pelo autor, com base na pesquisa realizada em Glossário de Arranjos e Sistemas Produtivos e Inovativos Locais da Redesist (LASTRES e CASSIOLATO, 2005, p. 2) 
Ao contrário da concentração industrial típica dos sistemas de produção de natureza fordistas, cada vez mais, parte da produção e dos serviços vem se concentrando no estabelecimento de novas relações sociais baseadas em interdependência e cooperação, convergindo para o conceito de redes, que traz implícita a ideia de integração dos fenômenos econômicos, políticos, sociais e culturais.

A ligação desse conceito com a ideia de aglomeração é um importante passo. A cooperação entre agentes ao longo da cadeia produtiva, calcada na experiência da Terceira Itália ${ }^{4}$, passa a ser cada vez mais destacada como elemento fundamental na competitividade. Através do fortalecimento da relação e articulação entre os agentes, distancia-se do entendimento de arranjos produtivos locais como simples aglomerações de empresas em uma determinada localização geográfica.

A interação entre agentes visa combinar potencialidades individuais e reduzir as dificuldades. $O$ fato de estarem concentrados no mesmo espaço geográfico facilita as relações comerciais e desenvolve laços de confiança e reciprocidade, sendo importante pontuar que isoladamente não seria possível aspirar a uma participação segura e crescente no mercado de atuação. Reunidos em torno de um APL, é possível fortalecer-se como grupo para participar da competição com os supostos líderes de mercado e conseguir melhorar a exposição de seus produtos.

Segundo Cassiolato e Szapiro (2003) a ideia de aglomerações torna-se explicitamente associada ao conceito de competitividade, principalmente a partir do início dos anos 1990. Chaves (2011) pontua que mudanças econômico/espaciais observadas no cenário mundial nessa época acarretaram ruptura nos paradigmas até então dominantes, o que implicou na ascensão de novos espaços produtivos.

Nessa época, no âmbito das universidades e dos programas federais e estaduais, iniciou-se o incentivo à formação de estruturas produtivas como uma possível solução econômica, visando o desenvolvimento regional e/ou nacional. Nesse contexto, o termo em inglês cluster ${ }^{5}$ assumiu uma terminologia local conhecida por Arranjo Produtivo Local. A noção de APL destaca o vínculo das unidades produtivas com o território, seja na relação específica de produção e distribuição, seja pela parceria com agentes públicos e privados voltados para capacitação tecnológica, gerencial e financeira.

Os APLs devem ser modelos a serem seguidos não apenas para 0 desenvolvimento regional, mas também para o fortalecimento da cadeia produtiva do setor e, por meio de cooperação e interação, promover a competitividade e a sustentabilidade.

\subsection{Desenvolvimento Sustentável e Valores do Território}

\footnotetext{
${ }^{4}$ A chamada Terceira Itália - região onde se localizam Milão, Turim, Bolonha, Florença, Ancona, Veneza, Modena e Gênova - surgiu no início dos anos 1970 e caracteriza-se pela existência de grupos de pequenas empresas, cuja principal estratégia é a inovação contínua e a utilização de métodos flexíveis de produção. Seu crescimento foi impulsionado pela formação de distritos industriais, estabelecendo um sistema de confiança e cooperação entre tais empresas. Essa região apresenta fortes vínculos de cooperação e grande estímulo à abertura de negócios próprios, criando um sistema integrado de produção, além de apoio governamental com o objetivo de promover o desenvolvimento econômico local, o que rendeu à região um dos mais altos níveis de renda per capita da Itália.

${ }^{5}$ Cluster refere-se à aglomeração territorial somente de empresas com características similares, enfatizando mais o aspecto da concorrência do que o da cooperação.
} 
Segundo Oliveira (2006) apud Alcoforado (2010), o desenvolvimento sustentável pode ser definido como o processo de crescimento das condições sociais, políticas, culturais, econômicas, educacionais e ambientais de uma comunidade, com base na tomada de consciência individual e uma responsabilidade coletiva sobre a realização de iniciativas locais, produtivas ou não.

Manzini e Vezzoli (2005) apud Alcoforado (2010) descrevem duas dimensões de uma sociedade sustentável: a dimensão econômica e produtiva e a dimensão social e cultural, que devem ser pontuadas de forma a demonstrar que o desenvolvimento sustentável não se restringe somente à esfera ambiental.

No âmbito do design, para Manzini e Vezzoli (2005), um dos principais desafios da atividade atualmente é desenvolver e suportar o desenvolvimento de soluções para questões mais complexas, que exigem visão mais abrangente, que envolva produtos, serviços e comunicação de forma conjunta e sustentável.

Bistagnino et al (2008) apontam que a abordagem linear do design emerge da atenção projetual limitada à construção de produtos e serviços que, de forma pontual, respondem às exigências do mercado, criando uma série de novas possibilidades. Essa abordagem não permite considerar os sistemas de valores sociais, culturais e éticos que constituem a verdadeira essência do produto ou do serviço. O papel do designer nessa nova visão é atuar como facilitador de processos e a atividade passa a ser entendida e aceita como um valor cultural adicionado ao projeto e um recurso estratégico para o desenvolvimento econômico e cultural de uma área, assumindo seu papel social.

De acordo com os autores estudados, percebe-se que o caminho não pode calcar-se na tentativa de "mudar ou salvar" o mundo, mas de, dentro de um cenário existente, buscar alternativas que possam ser trabalhadas em busca de soluções mais sustentáveis.

Segundo Albagli (2004), a expressão "valor cultural agregado" diz respeito aos diferenciais da cultura ou território de determinado local, que são utilizados a fim de aumentar a competitividade dos bens e serviços a eles associados.

Como passos fundamentais a serem considerados no fortalecimento da identidade de um território, deve-se considerar o mesmo enquanto um sistema com suas potencialidades. Esse conhecimento pode estruturar-se a partir das quatro dimensões do território, adaptadas de Albagli (2004).

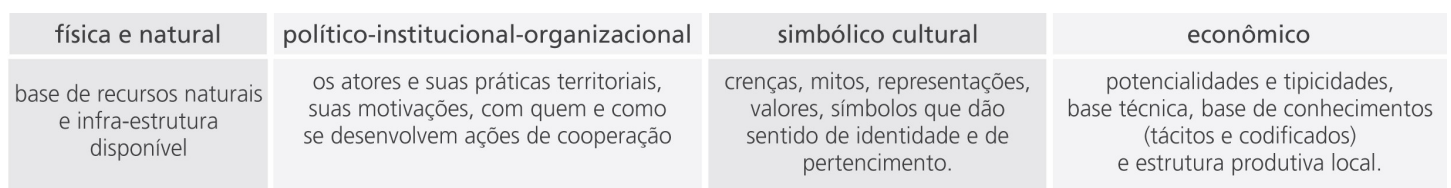

Figura 2 - Quatro dimensões do território. Elaborado pelo autor, adaptadas de Albagli (2004, p. 27).

O mundo contemporâneo tem testemunhado o surgimento e multiplicação de redes como um novo fenômeno organizacional. O conceito apontado neste trabalho é o de um tipo de organização horizontal não centralizada, em que cada núcleo participante é autônomo e capaz de tomar iniciativas.

Sabe-se que a inovação é o principal fator de agregação de valor e aumento da produtividade. O desenvolvimento do território depende, então, da construção e multiplicação de redes de atores locais, em busca de mudanças políticas, econômicas e sociais. 
No âmbito da economia, as redes facilitam a interação, articulação, cooperação e aprendizagem, possibilitando o conhecimento tácito, aquele que não está codificado e que é replicado pela troca de experiências, configurando-se, em muitos casos, como responsável pelas inovações.

Por essa perspectiva, compreende-se que a estratégia de promoção do desenvolvimento econômico regional através do fortalecimento dos APLs pode ser muito interessante na medida que interagem diversos atores e agentes do conhecimento na busca de inovação e competitividade do $A P L$, que passa a se configurar como um importante eixo de desenvolvimento econômico de uma região.

Nas regiões em que se identificam concentrações produtivas significativas de determinado setor, o estímulo aos APLs pode ser considerado como importante ferramenta estratégica de desenvolvimento local, pois se adequadamente conduzido, é capaz de auxiliar na indução do desenvolvimento regional, gerando importantes manifestações para o território, a sociedade e a economia.

Krucken (2009) aponta processos que o design pode facilitar e apoiar, em Arranjos Produtivos Locais, demonstrados na figura 3:

Identificação e exploração sustentável do potencial dos recursos e das competências situadas no território.
Desenvolvimento de uma cultura de co-produção de valores e processos produtivos colaborativos.

localmente, com base nos recursos, nas competências disponíveis e na riqueza cultural.

Processos colaborativos de inovação e aperfeiçoamento do design local, pelos quais se promova o diálogo de tradição e inovação e se fortaleça o sentido de pertença da comunidade.

\section{Fortalecimento da imagem do território e de seus
produtos e empresas. \\ Fortalecimento da imagem do território e de seus
produtos e empresas.}

Resgate de valores e da cultura local e desenvolvimento de produtos a partir de matérias primas alternativas disponíveis no território além de utilização de subprodutos e resíduos.

Projeto de novas interfaces e formas de intermediações entre os produtores e entre produtores e consumidores (redes e cadeias valores), envolvendo os recursos e potencialidades das empresas e do território;

Figura 3 - Processos que o design pode facilitar e apoiar em Arranjos Produtivos Locais. Elaborado pelo autor, adaptado Krucken (2009).

Dentro do contexto de território, Krucken (2009) defende a adoção de uma política cultural que respeite a cultura local e promova a ligação entre território, comunidade e produto, resultando em um consumo responsável e produtos de qualidade superior.

A abordagem do design aplicado ao território visa beneficiar tanto produtores como consumidores. Para isso, é necessário o planejamento de ações em nível sistêmico, pela colaboração de áreas diversas e o estabelecimento de redes favoráveis ao desenvolvimento local, com ênfase nos pequenos produtores. Além de produzir de acordo com o potencial e características locais, pequenos produtores associados tem mais peso, pois não se depende de uma única produção para a inserção do produto no mercado, o que diminui os riscos. Os APLs configuram-se como soluções para a organização desses pequenos produtores.

Ao se tratar de APLs, é importante destacar que o "maior desafio é canalizar forças (reconhecidas e latentes) presentes no território e apoiar um comportamento 
pró-ativo versus a colaboração e integração de interesses locais, de forma que as inovações se concretizem e tragam benefícios coletivos". (KRUCKEN, 2009, p.51)

\subsection{Possibilidades identificadas: o setor de gemas e joias}

Um dos maiores desafios enfrentados na transição para a sustentabilidade é o pensamento orientado aos sistemas integrados, (THACKARA, 2008). O autor defende que não é preciso pensar ou agir grande para mudar grandes sistemas e que pequenas ações de design podem ter grandes consequências, possivelmente positivas.

Pelo Termo de Referência para Política de Apoio ao Desenvolvimento dos Arranjos Produtivos Locais, elaborado pelo GTP APL - MDIC (Grupo de Trabalho Permanente para APLs (GTP APL), coordenado pelo Ministério do Desenvolvimento, Indústria e Comércio Exterior), um APL de Base Mineral deve ser balizado pela seguinte caracterização: dispor, num dado território, de um número significativo de empreendedores que atuem na cadeia produtiva mineral e compartilham formas percebidas de articulação, interação, cooperação, aprendizagem e mecanismos de governança. São incluídas não somente empresas, mas também outras instituições públicas e privadas voltadas à formação, capacitação e treinamento de recursos humanos, pesquisa, desenvolvimento, inovação, engenharia, promoção e financiamento do setor mineral (Associações, Sindicatos, Secretarias, Universidades, Instituições de Pesquisa, dentre outros).

\footnotetext{
São APLs constituídos por uma cadeia produtiva diversificada e que contempla desde a mineração em pequena escala, atuando desde a pesquisa e extração de insumos minerais, beneficiamento e transformação mineral, até o acabamento e comercialização do produto. No Brasil, os principais insumos e produtos da cadeia produtiva da indústria mineral, já caracterizados como APLs são: água mineral, agregados para a construção civil, ardósia, gesso, calcário e cal, cerâmica vermelha, cerâmica de revestimento, gemas e jóias, rochas ornamentais, e rochas e minerais pegmatitos. (LASTRES E CASSIOLATO, 2005, p.07)
}

Gemas e Joias integram o conjunto de APLs de Base Mineral que representam um valioso instrumento estratégico de articulação e integração de políticas de apoio ao desenvolvimento regional e local da mineração em pequena e média escala. (PERSPECTIVA MINERAL, 2011)

Martins e Merino (2011) destacam que o mercado tem evidenciado, cada vez mais, a necessidade do emprego do design, que deixa de ser visto apenas como adição de estética para o desenvolvimento consciente de projetos em toda a sua complexidade. Os autores falam sobre o potencial do design, se integrado a uma organização, desde a concepção de sua estratégia, passando por todas as fases de desenvolvimento e integrando outras áreas.

Desta forma, as tarefas do designer estão estreitamente relacionadas à execução de um projeto, mas também atentas a questões de maior alcance, como a sustentabilidade, a relação com o ambiente e o ser humano, o impacto da atividade do design na vida das pessoas, a responsabilidades com a cultura, com a ética, com os valores sociais e com os benefícios para a comunidade (SILVA e FIGUEIREDO, 2010). 
Martins e Merino (2011) destacam ainda uma vertente explorada atualmente pelas organizações que é do seu papel social, abordando mudanças que tragam qualidade de vida para todos. Para Thackara (2008), a ética e a responsabilidade podem fundamentar decisões de design sem restringir a inovação social e técnica que todos precisamos promover. Assim, pode-se inferir que a gestão pelo design, no âmbito dos Arranjos Produtivos Locais é um recurso que auxilia a organização, atuando como ferramenta competitiva e estratégica, inserindo elementos estéticos, de qualidade e valor, concretizando identidades, materializando culturas corporativas, podendo atuar na redução de complexidade, tempo e custo de produção.

O setor de gemas e joias pode ser tão competente como outros setores já consagrados da economia e com grande potencial para gerar emprego e renda. Segundo dados oficias do Instituto Brasileiro de Gemas e Metais Preciosos (IBGM ${ }^{6}$ ), o Brasil é responsável pela produção de $1 / 3$ do volume mundial de gemas e Minas Gerais é um dos maiores estados produtores. Composto em grande parte por pequenas unidades produtivas, o setor necessita de ações integradoras e cooperadas que fortaleçam todo o conjunto.

Sua matéria prima apresenta as características de um produto que mantém um lastro histórico, aliado à tradição de Minas Gerais como grande produtora. Além de seu valor econômico, possui grande reconhecimento mundial e é um exemplo de produto onde as novas tendências se aplicam, constituindo um cenário em potencial para o design. Isso acontece porque sua aceitação é comum em todo o mundo e existem muitos exemplos bem sucedidos de formas de exploração do produto de forma inovativa.

Os conceitos relacionados aos novos territórios do design, abordados nesse trabalho, podem ser inseridos na cadeia de valor do setor de gemas e joias, ampliando seu potencial de produto de exportação por meio de alto valor agregado. Por essa perspectiva amplia-se a inserção do design na cadeia produtiva do setor, desdobrandose em múltiplas possibilidades de intervenção e atuação, que podem ser exploradas em níveis de trabalhos mais aprofundados.

Ao longo dos trabalhos desenvolvidos, tanto os projetos de pesquisa e extensão, ilustrados pelos estudos de caso Joias do Mucuri $^{7}$ e Itaporarte $^{8}$ da dissertação de mestrado, foi possível identificar diferentes potenciais de agregação de valor no conjunto de atividades envolvidas nos vários níveis da cadeia de valor do setor apresentada no esquema ilustrativo da figura 4.

A ilustração gráfica representada abaixo sintetiza como o design pode ser transversal à cadeia de valor do setor, contribuindo em várias fases de seu desenvolvimento à criação de novos conceitos, marcas, produtos e serviços.

\footnotetext{
${ }^{6} \mathrm{O}$ Instituto Brasileiro de Gemas e Metais Preciosos - IBGM é uma entidade nacional, de direito privado, sem fins lucrativos, criada em 1977 com o objetivo de representar toda a cadeia produtiva do Setor de Gemas e Jóias.

${ }^{7}$ O Projeto Joias do Mucuri foi uma ação em uma Unidade de Inovação Tecnológica instalada em Teófilo Otoni, com o objetivo de ampliar a estratégia competitiva dos produtos do APL, por meio de renovação criativa e inovação tecnológica de empresas do setor de gemas e joias.

8 O Laboratório Itaporarte é uma mini plataforma produtiva com atividades voltadas ao desenvolvimento de Capacidade Tecnológica Própria na região de Coronel Murta, no Vale do Jequitinhonha, capacitando pessoas da comunidade para o desenvolvimento de produtos que tem como matéria prima descartes da extração de gemas preciosas.
} 


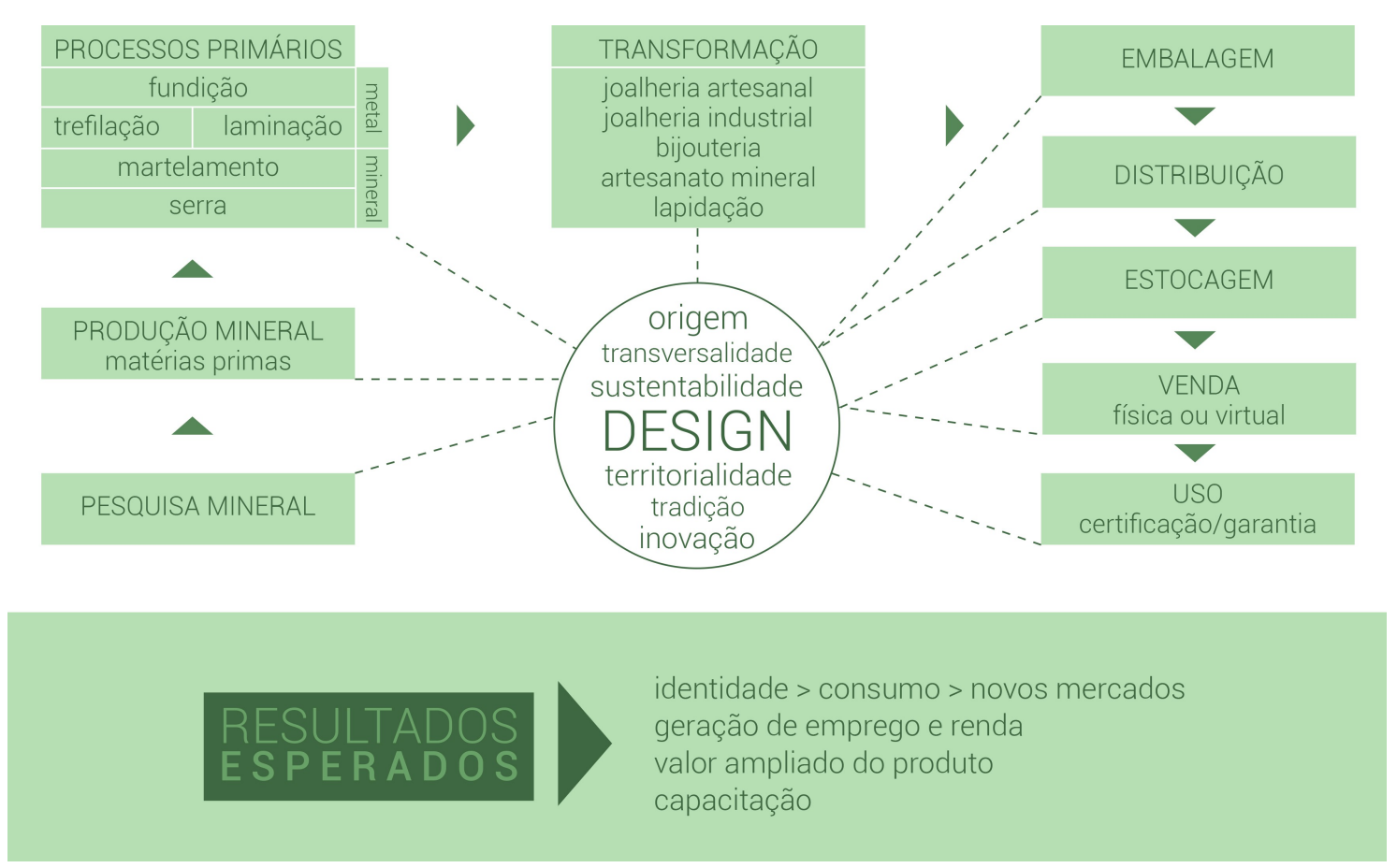

Figura 4 - Proposta de possibilidades de inserção do design no setor de gemas e joias. Elaborado pelo autor.

No nível um, a pesquisa já possibilita vislumbrar possibilidades de beneficiamento dos minerais, fase na qual o design atua junto ao planejamento, de forma a potencializar os recursos, beneficiamento e aplicação dos materiais.

A inserção do design pode, por exemplo, contribuir para a sustentabilidade econômica, social e ambiental a partir do aproveitamento dos rejeitos da produção mineral. Ao longo de toda a cadeia pode-se observar as possibilidades de inserção do design, atuando sempre em interação com outras áreas, a fim de abranger todos os aspectos relacionados à natureza complexa do setor de gemas e Joias. Pela vertente da gestão, a inserção do design na cadeia de valor aponta, além de ações em diferentes níveis da cadeia, para o necessário relacionamento entre os atores, de forma a haver uma integração entre os envolvidos nos diferentes níveis.

\section{CONCLUSÃO}

Os estudos desenvolvidos neste trabalho permitiram a observação de outros aspectos ligados ao desenvolvimento de projetos de design em comunidades, arranjos e unidades produtivas. O primeiro deles é a compreensão da necessidade, dentro de um projeto, de se conhecer a história, a cultura, as pessoas e as vocações dos indivíduos e suas comunidades, além da importância de sua realização de forma participativa, ao invés de assistencialista ou paternalista. A parceria entre diversos atores da comunidade é um fator de auto sustentabilidade do projeto.

Além disso, esta inserção pode ser vista como uma oportunidade de agregação de valor não só à cultura local como aos recursos humanos disponíveis na região. Pequenas ações educacionais e tecnológicas podem contribuir para uma real e positiva transformação social, econômica e ambiental e, que essas pequenas ações podem 
desencadear um processo gradativo de desenvolvimento local, que pode ser reproduzido em outras comunidades.

Arranjos Produtivos Locais não são inventados. Eles já existem, precisam ser identificados e apoiados por projetos eficazes, que coloquem na mesma linha de trabalho atores diversos como empresários, governos e instituições de ensino e pesquisa. Da mesma forma, arranjos e territórios não são iguais, não sendo possível estabelecer padrões e métodos muito rígidos na execução de um projeto. Cada projeto tem suas especificidades. É preciso entender o contexto, a rede de atores que se forma, as vocações, potencialidades e aspectos significativos que compõem a história local para buscar soluções adequadas às demandas nas diferentes realidades, o que implica em uma coordenação mais estratégica a médio e longo prazo.

A inserção do design pode ser o elo entre as diversas áreas do Arranjo, orientando seus objetivos e configurando-se como fator critico de sucesso, criando conexões, padronizando sequências de procedimentos e encontrando soluções que sejam fruto de estudos e pesquisas coordenados, realizados de maneira a gerar resultados inovadores obtidos por meio de um trabalho multi e interdisciplinar.

A análise da cadeia produtiva do setor de gemas e joias, vista da perspectiva do design contemporâneo sinaliza oportunidades de exploração e inovação, que podem contribuir à ampliação da sua estratégia de produto como identidade territorial.

\section{AGRADECIMENTO}

Os autores deste artigo agradecem à Fundação de Apoio à Pesquisa do Estado de Minas Gerais - FAPEMIG pelo apoio na pesquisa e publicação deste trabalho.

\section{REFERÊNCIAS}

ALBAGLI, Sarita. Território e Territorialidade. In: Territórios em movimento: cultura e identidade como estratégia de inserção competitiva. Org: Vinícius Lages, Christiano Braga, Gustavo Morelli. Rio de Janeiro: Relume Dumará/ Brasília, DF: SEBRAE, 2004.

ALCOFORADO Alcoforado, Manoel Guedes. Cultura e territorialidade em políticas sociais. P\&D Design - Anais do Congresso Brasileiro de Pesquisa e Desenvolvimento em Design, 9a. edição, 2010, São Paulo.

BISTAGNINO, Luigi; Innovare: in Che modo? In: GERMAK, Claudio. Uomo al Centro Del Progetto, Design per um nuovo umanesimo. Torino: Umberto Allemandi \& C, 2008. P.32-39

CANAAN, Raquel Pereira. Gemas e joias: a gestão pelo design aplicada à cadeia de valor de arranjos produtivos locais. 2013. 117 f. Dissertação (Mestrado) - Escola de Design, Programa de Pós Graduação em Design da Universidade do Estado de Minas Gerais, Belo Horizonte, 2013.

CASSIOLATO, José Eduardo; SZAPIRO, Marina. Uma caracterização de arranjos produtivos locais de micro e pequenas empresas. In: CASSIOLATO, José Eduardo; LASTRES, Helena Maria Martins; MACIEL Maria Lucia. (orgs). Pequena Empresa: cooperação e desenvolvimento local. Rio de Janeiro: Relume Dumará, 2003.

CASTRO, Maria Luiza A. C. de; CARDOSO, Juliana. 2010. Design estratégico: taxonomias e inserção em contextos contemporaneous. P\&D Design - Anais do Congresso Brasileiro de Pesquisa e Desenvolvimento em Design, 9a. edição, 2010, São Paulo.

CHAVES, Débora Almeida. 0 setor de gemas e jóias de Belém: Um arranjo Produtivo Local. 2011, 30f. (Ciências Sociais Aplicadas/Economia) - Universidade Federal do Pará, UFPA, Belém, 2011. 
DALLA VECCHIA, Raquel Virmond Rauen. Arranjos Produtivos Locais como Estratégia de Desenvolvimento Regional Local. Paraná: UECO, 2008.

FLEURY, Afonso Carlos Corrêa; FLEURY, Maria Tereza Leme. Estratégias empresariais e formação de competencias. 3a. ed. São Paulo: Atlas, 2004.

KRUCKEN, Lia. Design e território: valorização de identidades e produtos locais. São Paulo: Studio Nobel, 2009.

LASTRES, Helena M.M; CASSIOLATO, José E. Glossário de Arranjos e Sistemas Produtivos e Inovativos Locais - GASPIL. Rio de Janeiro, 2005.

LASTRES, Helena M. M; CASSIOLATO, José Eduardo. Estratégias para o desenvolvimento: um enfoque sobre arranjos produtivos locais do Norte, Nordeste e Centro Oeste brasileiros. Rio de Janeiro: E:papers, 2006.

MANZINI, Ézio. Design para a inovação social e sustentabilidade: comunidades criativas, organizações colaborativas e novas redes projetuais. Rio se Janeiro: E-papers, 2008.

MANZINI, E.; VEZZOLI, C. O desenvolvimento de produtos sustentáveis: os requisitos ambientais dos produtos industriais. São Paulo: Editora da Universidade de São Paulo, 2005.

PERSPECTIVA MINERAL. No. 01, ano 01, 2009.

Disponível em: < http://www.mme.gov.br/mme> Acesso em: 14/02/2012.

PORTER, Michael E. Custers and the new economics of competition. Harvard Business Review, v. 76, no. 6, 1998.

REDESIST - Rede de Pesquisa Interdisciplinar do Instituto de economia da Universidade Federal do Rio de Janeiro, formada em 1997, em parceria com outras universidades e institutos de pesquisa do Brasil e do exterior. Disponível em <www.redesist.ie.ufrj.br>.

SACHS Ignacy. Caminhos para o desenvolvimento sustentável. Rio de Janeiro: Ed. Garamond, 2009.

SILVA, Carina Scandolara da; FIGUEIREDO, Luiz Fernando. Abordagem Sistêmica da Gestão de Design em Microempresas e Empresas de Pequeno Porte (MPEs). P\&D Design - Anais do Congresso Brasileiro de Pesquisa e Desenvolvimento em Design, 9a. edição, São Paulo, s/p 2010.

TATSCH, Ana Lucia (coord). Análise do mapeamento e das políticas para arranjos produtivos locais no sul, sudeste e centro oeste do Brasil. Rio de Janeiro: REDESIST, 2010. (relatório final)

TEIXEIRA, Maria Bernadete Santos (org). Projeto Itaporarte: Capacitação tecnológica na unidade produtiva de Coronel Murta com vista ao aprimoramento nos processos de inovação e lapidação de materiais descartados dos corpos pegmatíticos aplicados a acessórios e artesanato mineral. Relatório final o projeto financiado pela FAPEMIG (TEC 2248/05). Belo Horizonte: UEMG, 2007.

TEIXEIRA, Maria Bernadete Santos. Anexo B Design de Produto. In: SOUZA, Maria Cezarina Vítor de (org.) Projeto ampliação e consolidação da unidade de inovação tecnologia em gemas e joias do APL de gemas e artefatos de pedra de Teófilo Otoni como um centro de referencia do pólo mineral e metalúrgico. Relatório final o projeto financiado pela FAPEMIG. Belo Horizonte: UEMG, 2011.

THACKARA, John. Plano B. O Design e as Alternativas Viáveis em um Mundo Complexo. Virgília/Editora Saraiva, 2008

VAHL, Fabricio Peter. Ciclo de vida e estágios de desenvolvimento de arranjos produtivos locais: o caso do APL de turismo da grande Florianópolis. In: Revista Iberoamericana de 
Engenharia Industrial. Periódico da Área de Engenharia Industrial e áreas correlatas. Vol. 01, no. 02, p. 101-118, 2009. 